The Geneva Papers on Risk and Insurance, 17 (No. 64, July 1992), 393-405

\title{
Insurance Implications of Climatic Change
}

\author{
by Andrew F. Dlugolecki*
}

\section{Introduction}

This paper considers the implications for the insurance market of climatic change. The first step is to restate recent developments in the insurance of weather damage, particularly in the United Kingdom. Then the long-term history of weather events is reviewed to provide a perspective for current projections of climatic change. These can then be translated into possible effects on the insurance market. While it may be thought that the UK is a rather restrictive case-study, this is not so: it is a well-developed market, with unexpectedly large exposures to weather losses, and with a mixture of climate types (predominantly maritime).

\section{Recent trends in cost}

Figure 1 shows the winter weather losses suffered by the UK company insurance market, measured in hundred million pounds sterling at 1987 values for the period 1960-90. The predominant source of loss was storm, although there were several freeze events between 1979 and 1987. The freeze of February 1991 cost about $£ 150$ million in 1987 values (not shown).

The most notable feature is the increase in the scale of events, from around $£ 100$ million in most of the period to $£ 1,000$ million for the October 1987 'hurricane', and even more in 1990.

The data itself is imperfect for several reasons. It excludes losses on business interruption, and the accident classes including motor, and of course uninsured losses. The definition of an event is somewhat inconsistent. It is also notable that during the period there were no major floods in Britain, although there were on the Continent.

Although the industry does not publish statistics on weather losses other than storms and freeze, in fact subsidence of buildings is also a major problem. Since the inception of this cover in 1971, the annual cost has risen to probably \& 600 million in 1990. This has been exacerbated by the shift in regional rainfall in Britain, with less than average precipitation over the South-East clay belts.

* Chief Manager, Operations, General Accident Fire and Life Assurance Corporation p.l.c., Perth, Scotland. Paper presented at the Fourth International Geneva Association Conference 29th October 1991, William Kent House, London. 


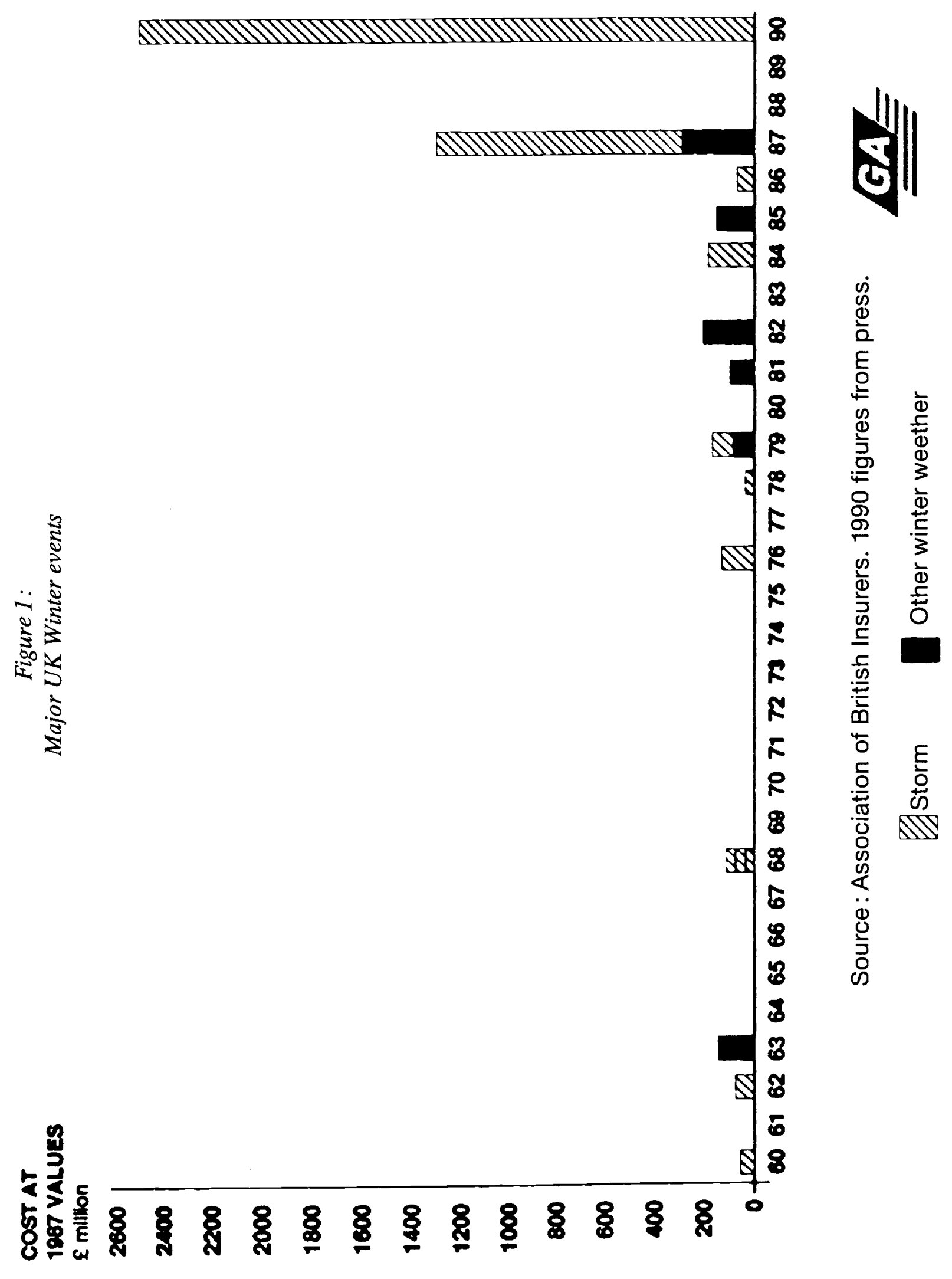


Returning to windstorm, Figure 2 shows the worldwide picture, using statistics from the Munich Re. The annual frequency of severe storms has increased each decade, from 0.8 in the 1960 's to 4.0 in 1990 . The pattern in 1991 already looks similar to 1990 . The damage caused (including uninsured losses) also rose significantly from $\$ 2$ billion to $\$ 14$ billion, while the insured losses rose from $\$ 0.5$ billion to almost $\$ 10$ billion.

Figure 2:

Major windstorms worldwide 1960-90

$\begin{array}{lcccr} & \begin{array}{c}1960 \text { 's } \\ \text { per year }\end{array} & \begin{array}{c}1970 \text { 's } \\ \text { per year }\end{array} & \begin{array}{c}1980 \text { 's } \\ \text { per year }\end{array} & \begin{array}{r}1990 \text { 's } \\ \text { alone }\end{array} \\ \text { No. of windstorms } & 0.8 & 1.3 & 2.9 & 4.0 \\ \text { Damage \$ B } & 2.0 & 2.9 & 3.4 & 14.1 \\ \text { Insured \$ B } & 0.5 & 0.8 & 1.7 & 9.8\end{array}$

Values at 1990 prices

Data from Munich Re

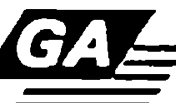

General Accident

Questions immediately spring to mind. How much of these increases are due to changes in the weather itself? Are the increases due to changes in the insurance market, other than the weather? If so, what are the important factors? Is the apparent deterioration simply due to a change in statistical classification?

\section{Market pressures on claim costs}

There are several factors inherent in the UK insurance market which have tended to raise the cost of events independently of the weather. Firstly, the population is now wealthier, with more possessions to insure (e.g. in 1974 video recorders were non-existent, but $64 \%$ of households owned one in 1990).

Secondly, these possessions themselves are becoming more vulnerable, and are located on more vulnerable sites. The development of electronic consumer goods with delicate components, and the increasing expenditure on soft furnishings are examples of the former. As far as sites go, buildings are often constructed on exposed hillsides, or on floodplains; while trees placed near houses for amenity, also raise the problems of storm damage and root invasion/soil dessication. 
As consumer wealth grows, people take more advantage of insurance. This elasticity of demand is a well-known feature of the insurance market, which causes exposure to increase more rapidly than the growth of GNP. The proportion of households with contents insurance grew from $70 \%$ in 1972 to $76 \%$ in 1982 , although it has stagnated since then.

A fourth factor is that the cover available is now much wider. Subsidence was only introduced in 1971. Flood insurance for buildings was only made widely available in 1961, after considerable political pressure. The use of deductibles to limit claims has been spasmodic - and after each hike they have been eroded swiftly by monetary inflation. The basis of cover was greatly extended with the advent of 'New for Old' in the Seventies, because the elimination of depreciation means that betterment is now included in the computation of losses.

There has also been a major shift in policyholders' behaviour. They have become more confident of making claims following damage to insured property. This is no doubt due to several influences, including consumerism (assert your rights), simpler insurance documents (plain English) and publicity at the time of disasters (storm is not an excluded 'Act of God'). It must also be said that changing moral attitudes lead to exaggerated, or even false claims.

Two factors which operate in many countries are the general increase in urbanisation, and the total number of inhabitants. However, these are not really important in the UK, since population growth is very slow, and the degree of urbanisation has been very high for many years.

Finally, inflation tends to magnify the apparent losses. No single deflator is apropriate, but because of its common use, the Retail Price Index has been used to standardise the costs in this paper.

\section{Climatic pressures on cost}

With so many "market" pressures on claim costs, is any of the increase in claim costs due to climatic variables? This can be confirmed in three ways: indirectly; by consideration of the frequency of events; and also by direct consideration of weather records.

Indirectly, one can consider whether claim costs have risen generally to the same extent that they have in 'catastrophic' circumstances. The volume and cost of the weather related claims on "normal" or non-catastrophic days, does not show the ten-fold increase which has happened for the events defined by the ABI. There is an increase which shows the influence of the other factors, but it is a much smaller one. This implies that either the catastrophic weather is more "catastrophic" now, or that some special effect operates in catastrophes to increase their costs particularly. Such special effects do exist: for example, less rigorous control on claims; higher repair costs due to supply shortage; but not to the extent that they could bridge the gap between 'normal' and 'catastrophic' patterns.

The number of events defined by the ABI as 'catastrophic' has varied - there were 6 in the Sixties, 4 in the Seventies, and 7 in the Eighties. However, the difficulty with this approach is that the definition is not rigorous. For example the storms of 1990 are amalgamated into one "event", and sometimes events are not identified at all. 
The third method, looking directly at how weather patterns have changed is the most satisfactory approach, but it does require some space to explore, and so it is deferred to a later section. Suffice it to say here, that investigation shows that the mid-Twentieth Century was unusually quiet in weather terms, that since then there has been a definite tendency to warm conditions, and that this pattern implies more violent and more frequent storms.

Given that there has been a shift in climatic factors towards more extreme weather, what does this mean for insurers? Figure 3 shows that the climate-to-cost effect is not a straight line. Each triangle in the diagram represents the "burning cost" on domestic buildings in one postal district in South-East England, placed on the diagram according to the maximum windspeed and the actual burning cost (claims cost / sum insured). The curve rises so steeply, that a $5 \mathrm{mph}$ increase in windspeed roughly doubles the burning cost.

The general level of losses in the October $1987(87 \mathrm{~J})$ event is interesting. In the worst hit districts i.e. those at the top of the diagram, $50 \%$ of properties were damaged, but the burning cost was only $1 \%$. This is much lower than the burning cost for tropical hurricanes, and shows how much room there is for deterioration - since claims only amounted to $1 \%$ of the sum insured, there was a further $99 \%$ potential (not to mention additional benefits like temporary alternative accommodation)!

This exponential pattern is typical. The same sharp curve has been found for freeze, drought and flood. Thus any tendency to more extreme conditions means that claim costs will rise disproportionately.

Finally it should be noted that such extreme events may occur as a result of random combinations of effects - for example, hydrologists reported the flood level in Towyn in February 1990 as equivalent to a 1000 year return period. It occurred due to the combination of high tides, storm surge and wave height, none of which was so extreme in itself. Another example is that a storm accompanied by rain may cost $25 \%$ more than a dry storm, owing to damage to the internal structure and contents of the buildings.

\section{Initial market reaction}

Faced with these problems, insurers have examined four remedies, with varying emphasis. The first method is to LIMIT THE DIRECT RISK, by means of selective underwriting and increased deductibles but there are some problems. Selection of property risks is difficult to introduce in personal lines, since the use of surveyors is generally uneconomic. High storm or frost hazard is not so easily identifiable as subsidence or flood. Deductibles can be effective in removing small claims, but they have marketing disadvantages, and may provoke over-charging by repairers to "compensate" for the non-insured deductible.

The second method is to CONTROL THE DAMAGE once it has occurred, by providing information before the incident, by offering free advice about emergency repairs on 24 hour telephone helplines to claimants, and by tying repairers to the insurance company in order to improve the quality and cost-effectiveness of repair work. While these steps might encourage some claims, the chance of property deteriorating after the initial incident is reduced.

The third method is to TRANSFER THE ACCEPTED RISK. The conventional solution is through reinsurance, which certainly proved cost-effective in the Eighties! The bulk of the major catastrophe costs was actually paid by reinsurers, although the direct insurers 
Figure 3:

Storm Cost $v$. Windspeed (October 1987)

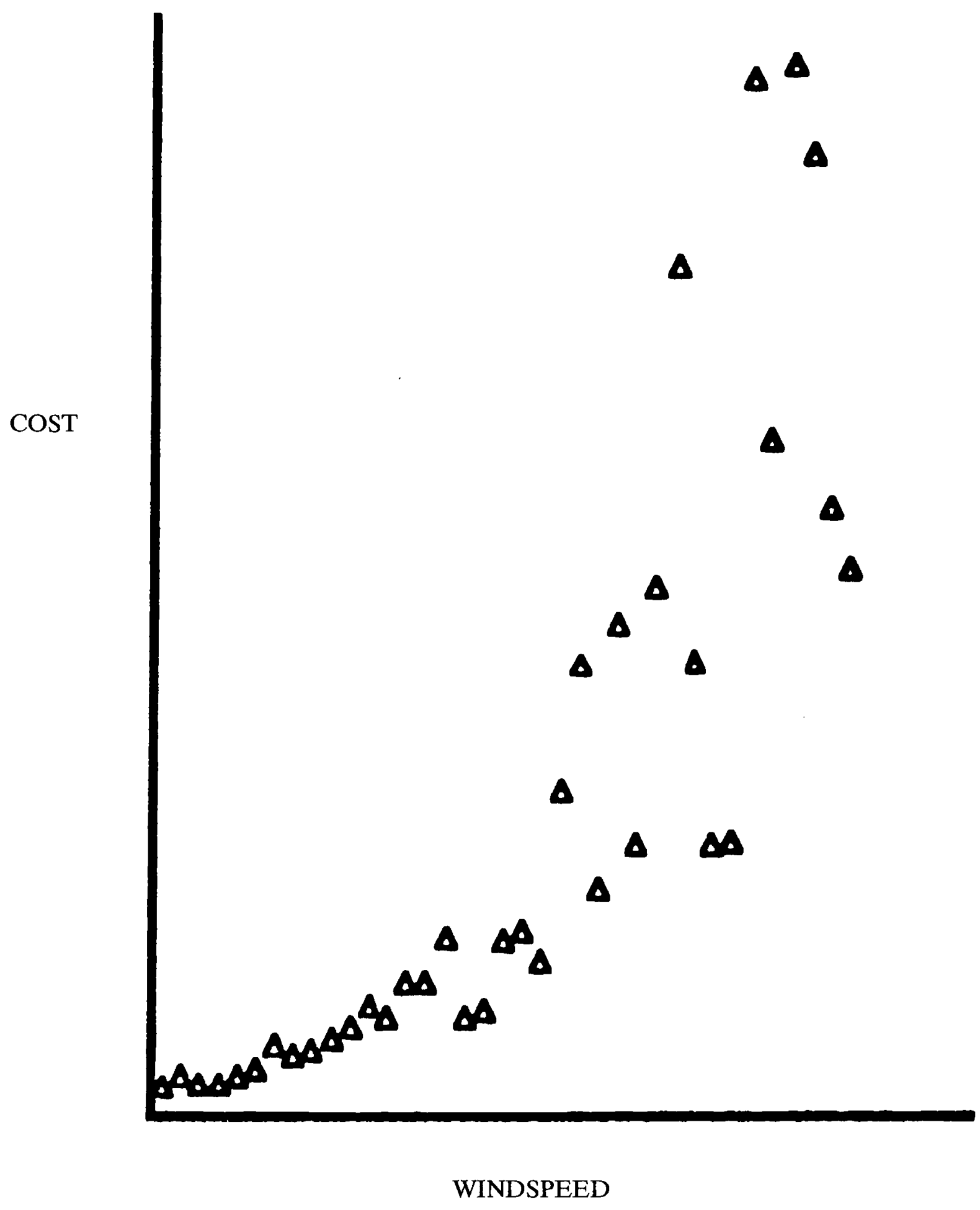


took the public credit for settling the claims. However, the availability and pricing of reinsurance has changed dramatically, ending this era of cheap "working" cover. An interesting development is to attempt to find a third party who may have contributed to the catastrophe in a way which could be deemed negligent. This could constitute a claim on the third party's liability covers. Such a claim could be magnified by the inclusion of uninsured property losses. Perhaps the most obvious example of this would be where a flood protection collapsed through poor maintenance.

Finally, the insurer can PRICE THE PRODUCT to incorporate the cost of the higher catastrophe risk. In competitive times, there is a great reluctance to be the first to increase premium rates. This is compounded by the absence of a consensus on the catastrophe risk. The October 1987 hurricane was almost written off as a 1 in 300 year event (like the 1976 drought!), but this was hardly tenable after 1990 European Winter Storms. The pricing approach is the only sound solution, although it may be supported by a mixture of the three other strategies.

\section{Historical climatic patterns}

Having reviewed briefly how the insurance market has been affected by weather catastrophes since 1960, let us now review the available evidence on historical weather patterns, before looking at climatic predictions, and their possible implications for insurers.

Scientific records in the UK only really started about 330 years ago. They relate primarily to temperature, though data on rainfall became available about 70 years later. Data on other variables such as windspeed and cloud cover took much longer to develop. Using indirect methods it appears that OVER THE PAST 1000 YEARS the 50 year average temperature in the British Isles has stayed within a range of about $1^{\circ} \mathrm{C}$ of today's average, sometimes above, sometimes below. This "narrow" range has been associated with major impacts on society. In the warm early medieval period, marginal land was exploited, and the population rose. Vineyards were found much further north in England and the quality of English vintages led to economic war with France. During the Little Ice Age (15901850), the Thames froze over repeatedly, and there were instances of Eskimos arriving in Scottish ports as their kayaks were driven south. Family formations was affected too; in the warmer period, marriages took place early, but in harsher times, daughters tended to remain on their parents' farm, and married much later.

There have been disasters during this millenium, which if repeated today would be extremely costly. In the UK, there have been several devastating sandstorms (e. g. Culbin 1694), coastal inundation (e.g. East Coast 1953), drought (entire UK 1976). In addition volcanic dusthaze can affect the weather (e.g. 1816, "the year without a summer"). Continental Europe has seen even more spectacular disasters; the most notable perhaps being the Decade of Disaster 1338-48 which suffered massive riverine flooding, then very cool summers, then very hot conditions with locusts, and finally the Black Death. These incidents are mentioned to emphasise that our current conditions are not extraordinary, but are within the range of historical experience. Using a history of 3 years (for property insurance rating) or even 30 years (for meteorological purposes) suddenly seems irrelevant for rating weather catastrophes.

The scientific records for the UK help to shed some light on current patterns. Monthly average for rainfall are available from 1727 , and for temperature from 1659 . The rainfall 
data does not exhibit any clear trends over the period, and so will not be considered here. However, the temperature data is worth further investigation. Since damage to property follows from extremes of temperature, it is useful to define extreme months as follows: for each calendar month, define those with temperatures in the top $10 \%$ of the observations for that month as "hot". For example July 1983 was the hottest July in the records and so qualifies as "hot". Similarly January 1989 was the 8th warmest January, and also qualifies as "hot". A similar procedure is followed to give "cold" months.

This can be developed further to give a measure of whether a period was "hot" or "cold" in character, by summing the number of "hot" months and subtracting the number of "cold" months during the period. If the balance is positive, the period was "hot", and if negative, "cold". This is illustrated in Figure 4, for consecutive 30 year periods from 1660 to 1989 . The chart shows 60 years of intense "cold", followed by a "hot" period and then generally cool conditions up to 1929 . Since 1930 we have been in a "hot" phase. Remember that within a "cold" period there can still be "hot" months (e. g. in 1665 the Great Fire of London, followed in 1666 by the Great Plague - both related to warm summers).

The fact that 1960-89 was not as "hot" as 1930-59 seems odd given the general concern about global warming. Closer examination shows that in fact there was a regression in the Sixties, but since then there has been a progressive warming. Figure 5 shows this pattern quite clearly. The definition of "hot" and "cold" means that the frequency of each extreme should be 1.2 per annum, since $10 \%$ is the criterion, and there are 12 months in the year. The table shows that the frequency of cold extremes has been below this level consistently since 1960. The frequency of "hot" months started just below the expected level, at an annual rate of 1.0 in the Sixties rising progressively to 5.0 for the Nineties (admittedly only up to September 1991).

This warming pattern takes on great significance if we consider the relationship between storminess and temperature. Professor $\mathrm{H}$. Lamb recently published a work on North Sea storms containing a valuable list going back to the Sixteenth Century. The 1990 storms occurred just after his data collection, but we can select a 300 year period, 1690-1989, for which we have data on storminess and monthly temperatures in Central England. Figure 6 shows "hot" winter months have an $11 \%$ chance of a severe storm, as defined by Professor Lamb. "Medium" winter months have a 7\% chance, and "cold" winter months only a $3 \%$ chance. The severity of the storms is also related positively to the temperature. The storms of 1990 confirm this pattern since they were severe, and the temperatures in that winter were well above average. Indeed 1990 was the warmest year observed scientifically around the world. In general the trend towards increasingly warmer weather since 1960 has paralleled the increase in catastrophe costs. ${ }^{1}$

\section{Global warming and natural perils}

Since the Industrial Revolution began in the Eighteenth Century, human activity has caused subtle but important differences in the Earth's atmosphere, adding to the natural carbon dioxide and methane and introducing artificial gases like the CFC's.

The consensus of scientific opinion is that this will give rise to significant climatic change. Most notably, the general temperature level will increase steadily, and the sea will

${ }^{1}$ The values in Figure 6 are provisional, subject to revision through private correspondence with Professor Lamb. 


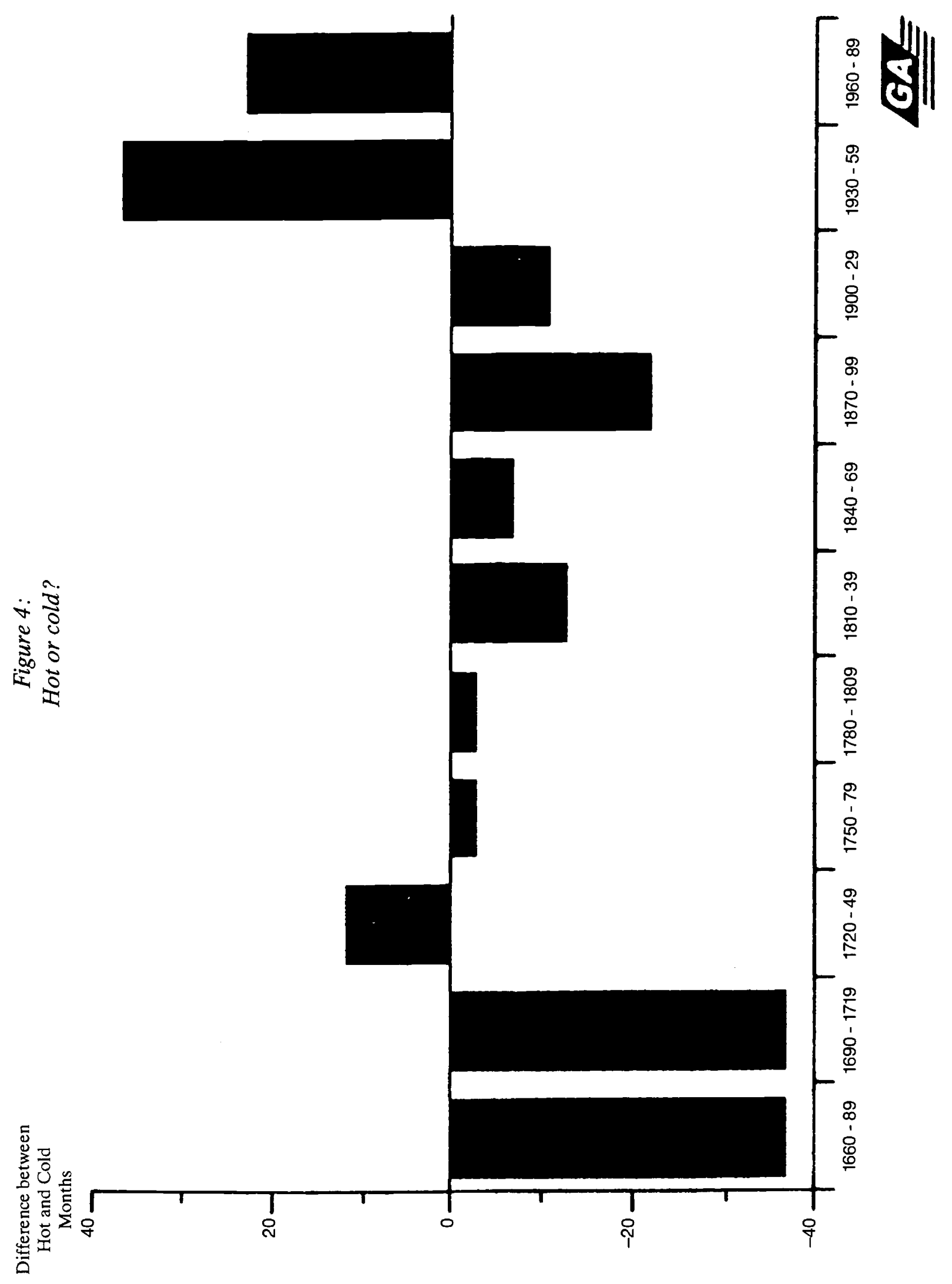


also rise gradually. There is still considerable uncertainty about the extent and timing of these changes, and there are even sceptics who dispute the causal link between man-made gases and climatic change.

\begin{tabular}{|c|c|c|c|c|}
\hline & \multicolumn{3}{|c|}{$\begin{array}{c}\text { Figure 5: } \\
\text { UK since } 1960 \\
\text { Annual frequency of extremes }\end{array}$} & \multirow[b]{2}{*}{ 1990's } \\
\hline & 1960’s & 1970’s & 1980's & \\
\hline Hot months & 1.0 & 1.6 & 2.1 & 5.0 \\
\hline Cold months & 0.7 & 0.9 & 0.8 & 0.6 \\
\hline \multirow[t]{2}{*}{ Extreme months } & 1.7 & 2.5 & 2.9 & 5.6 \\
\hline & $\mathrm{Ge}$ & Iccident & & \\
\hline
\end{tabular}

Figure 6:

Winter storms and temperature 1690-1989

Type of

Winter Month

Warm

Medium

Cool

\section{Storm}

Frequency

$11 \%$

$7 \%$

$3 \%$
Storm

Strength

4,050

2,352

333

Temperatures from Manley series

Storms data from Lamb

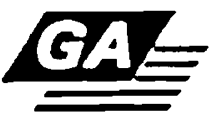

General Accident 
Figure 7 presents the "best guesses" of UK scientists, for selected parameters in the UK in the years 2010, 2030 and 2050. In summer the warming will affect the whole UK equally, but in winter there, will be a reduction in the temperature difference between Scotland and England. The scale of the changes by 2030 will take the UK beyond the bounds of historical experience in the last 1000 years. These developments will mean a greater chance of extreme temperatures. The last row of the table translates this into layman's terms, showing that by the year 2050 one year in three could experience a drought like that of 1976 . Finally, the sea-level will rise by about $30 \mathrm{~cm}$ during the period. This does not sound a lot, and can certainly be handled by modern engineering techniques, but it would add noticeably to the damage caused by on-shore storms.

\begin{tabular}{|c|c|c|c|}
\hline \multicolumn{4}{|c|}{$\begin{array}{c}\text { Figure } 7: \\
\text { Global warming in the UK }\end{array}$} \\
\hline YEAR & 2010 & 2030 & 2050 \\
\hline \multicolumn{4}{|l|}{ Temperature $\left({ }^{\circ} \mathrm{C}\right)$} \\
\hline Summer & +0.7 & +1.4 & +2.1 \\
\hline Winter (South) & +0.9 & +1.5 & +2.2 \\
\hline Winter (North) & +1.1 & +2.1 & +3.5 \\
\hline Sea Level $(\mathrm{cm})$ & +10 & +20 & +30 \\
\hline Chance of 1976 drought & $60: 1$ & $10: 1$ & $3: 1$ \\
\hline \multicolumn{4}{|c|}{ General Accident } \\
\hline
\end{tabular}

Looking further afield, Figure 8 summarises the predictions of the IPCC, a body of scientists convened by the United Nations to consider Global Warming. These figures are now seen as slightly too high, but they confirm the message that the changes will be large by historical standards, and could be accompanied by serious water resource problems.

It must be remembered that all these forecasts are "mid-range". In practice there is considerable uncertainty about the scale and speed of the linkage between atmospheric gases and climate. The more distant projections could be affected by changes in government policy e.g. energy usage. All of the figures ignore natural climatic trends - there is some evidence to suggest that we are currently in a natural warming phase anyway.

If Figure 6 is a reliable guide, then the warmer conditions could be associated with more frequent, violent storms particularly in Winter. (Other writers have noted that the 
parallel increase in sea surface temperature may extend the breeding grounds and active season for tropical storms). More speculatively, it is possible that the UK will take on a more continental aspect in Summer, with an increase in thunderstorm activity. Drought (and subsidence) will be a problem due to the faster evaporation in warm air, and the speedier runoff from dry ground. Woodland fires will also be more frequent.

\begin{tabular}{|lcc|}
\hline & Figure $8:$ & \\
& U.N. forecasts (year 2030) & \\
& Temperature $\left({ }^{\circ} \mathrm{C}\right)$ & More Drought \\
US Prairies & +3.0 & Yes \\
India & +1.5 & No \\
Sahel & +1.5 & $?$ \\
Mediterranean & +2.0 & Yes \\
Australia & +2.0 & $?$ \\
& $\underline{\mathbf{C}}$ & \\
& General Accident & \\
\hline
\end{tabular}

Freshwater flooding may be a local problem due to convective storms in Summer, and perhaps swifter snowmelt in the Spring. The threat of coastal inundation will increase steadily, compounded by geological ground movement in the Southern North Sea Basin.

There could be benefits from less severe winters, but the damage which could result from even a moderately cold winter would probably be disproportionately large as society would be less well prepared for such events.

We can expect to see new meteorological records as the climate changes, and customary relationships may probably break down - for example the differential between day and night time temperatures might alter.

\section{The effects on the insurance industry}

The direct effects of the physical changes described in the previous section will be greater losses on the property accounts, due primarily to storm damage. There will be a significantly higher chance of catastrophic flood losses, but still with a much lower frequency than storms.

Further classes of insurance may be affected such as transport, business interruption, liability and personal accident, partly due to the increased severity of events, partly due to attempts to transfer costs out of the harassed property account.

As we have seen already, market trends will exacerbate the climatic trends, owing to wider cover, increasing exposure and exaggerated claims. Governments in mature economies 
will use the insurance market to handle the financial impact of natural perils. Two clear examples of this were the introduction of flood cover for domestic buildings in the UK, and more recently the imposition of "catastrophe" cover on property policies in France. In response, insurers will experiment further with combinations of the four strategies of limiting the risk, controlling the damage, transferring the risk, and correct pricing. The industry as a whole will become more involved in risk management, and will try to influence construction standards, sea defences, land use and tree management. Inspection of individual claim files has shown that damage is often caused by poor workmanship in building, and trees are obvious hazards at times of drought or storm.

International insurers will be exposed to the greater chance of combinations of events. Furthermore, with the effective absence of any upper aggregate limit on claims (other than the sums insured), losses in smaller territories could provide crippling to even large companies. There will be increasing pressure on tax authorities to give favourable treatment to reserves intended to smooth out claims volatility. This will assume some prominence in EC discussions on harmonisation.

\section{Summary}

This paper has demonstrated that there has been a real increase in weather losses, partly due to market dynamics, partly due to climatic factors. Historically even small climatic changes have had big social and economic effects.

Global warming will continue the current trend towards months with high temperatures. This can be expected to result in more property damage, largely from storms. There will also be important indirect effects for insurers. Most crucially, the financial consequences could be critical.

\section{REFERENCES}

Climate Change Impact Review Group. The Potential Effects of Climate Change in the United Kingdom (HMSO 1991)

Conference Reports, produced by DYP / IRRG, London:

UK Weather Catastrophe - 4 May 1988

The Greenhouse Effect - 21 February 1989

Changing Weather Patterns - 22 February 1990

How to Deal with Changing Weather Patterns - 21 February 1991

DLUGOLECKI, A. F., Climate Hazards in the UK - What Next?, at CII Annual Conference, 27 September 1990

GRIBBIN, J., Hothouse Earth, Bantam Press (1990)

LADURIE, E. Leroy, L'Histoire du Climat depuis L'An Mil, Flammarion, Paris, 1983

LAMB, H., Climate History and the Modern World, Methven, 1982.

LAMB, H., Historic Storms of the North Sea, British Isles and North West Europe, Cambridge University Press (1991). 